\title{
Fatigue Resistance Characterization of Warm Asphalt Rubber by Multiple Approaches
}

\author{
Jiangmiao $\mathrm{Yu}^{1}{ }^{1}$, Xianshu $\mathrm{Yu}^{1}{ }^{1}{ }^{\mathbb{D}}$, Zheming Gao ${ }^{2}$, Feng Guo ${ }^{3}$, Duanyi Wang ${ }^{1}$ and Huayang $\mathrm{Yu}^{1, *}$ \\ 1 School of Civil Engineering and Transportation, South China University of Technology, \\ Guangzhou 510006, China; yujm@scut.edu.cn (J.Y.); 201721008652@mail.scut.edu.cn (X.Y.); \\ tcdywang@scut.edu.cn (D.W.) \\ 2 Sonny Astani Department of Civil and Environmental Engineering, University of Southern California, \\ Los Angeles, CA 90089, USA; zhemingg@usc.edu \\ 3 Department of Civil Engineering and Environment, University of South Carolina, Columbia, SC 29205, USA; \\ fengg@email.sc.edu \\ * Correspondence: huayangyu@scut.edu.cn; Tel.: +86-188-9883-7614
}

Received: 3 August 2018; Accepted: 27 August 2018; Published: 31 August 2018

check for updates

Featured Application: This work provides reference for selecting appropriate approaches to evaluate the fatigue characteristics of rubberized asphalt specimens containing warm mix asphalt additives or other modifiers.

\begin{abstract}
Warm asphalt rubber (WAR) mixture is a sustainable paving material with advantages including waste recycling and noise reducing. A comprehensive understanding of the fatigue performance of WAR specimens is helpful to its wide application. However, research on evaluating the fatigue performance of WAR binder and mixtures is very limited. This paper applies five fatigue analysis approaches to evaluate the fatigue life of WAR samples with three different warm mix asphalt (WMA) additives. The conventional $G^{*} \sin \delta$, linear amplitude sweep (LAS), indirect tensile fatigue test (ITFT), and four-point bending beam (4PB) test were conducted based on available standards. In addition, a novel shear fatigue test was performed on WAR mortars. Test results indicated that the incorporation of crumb rubber has a significantly positive effect on fatigue resistance. WAR with chemical and foaming additives exhibited a poorer performance than asphalt rubber (AR), but their fatigue performance was still greatly superior to the non-rubberized samples. Finally, LAS as well as mortar shear fatigue and $4 \mathrm{~PB}$ tests provided the same prediction of fatigue resistance, while the results of $G^{*} \sin \delta$ and the ITFT were inconsistent. It is recommended to use LAS, the mortar shear fatigue test, and the $4 \mathrm{~PB}$ test for the fatigue resistance evaluation of rubberized specimens. The validation of the findings with more materials and field performances is recommended.
\end{abstract}

Keywords: multiscale characterization; rheology; mechanical properties; warm asphalt rubber; fatigue behavior

\section{Introduction}

Fatigue cracking is one of the most common types of distress that occur in asphalt pavement. The adhesive and cohesive performance of asphalt mastic deteriorates after repeated traffic loading together with the ultraviolet-irradiation aging. Fatigue cracks develop gradually within asphalt layers throughout the service period. Fatigue cracks always bring roughness and pothole concerns, eventually leading to the disintegration of the whole pavement surface. Therefore, a comprehensive understanding of asphalt fatigue is essential for the construction and maintenance of better flexible pavements. Previous studies have proposed several evaluating methods to predict the fatigue life of 
asphalt materials, such as the Superpave fatigue factor $\left(G^{*} \sin \delta\right)$ test [1] and linear amplitude sweep (LAS) test [2] for asphalt binder, the shear fatigue test for asphalt mortar [3], and the indirect tensile fatigue test (ITFT) [4] and four point bending beam (4PB) test [5] for asphalt mixture. Although the above methods are mostly based on relationships between initial stress/strain and loading cycles to failure with different stress or strain levels, their predictions have sometimes contradicted each other, especially when new materials or additives with more complicated properties are incorporated [6].

Asphalt rubber (AR) mixture is considered a sustainable paving material as it consumes abundant waste rubber tires. Due to the incorporation of crumb rubber modifier (CRM) into asphalt fractions, the components of modified binder become more complex due to the interaction among various components and swelled CRM's particle effect [7]. AR has attracted great interest for its superior mechanical properties and tire-road noise reduction function $[8,9]$. However, AR pavement should be constructed at an elevated temperature $\left(175^{\circ} \mathrm{C}-200^{\circ} \mathrm{C}\right)$ due to its high-viscous binder behavior. Recently, warm mix asphalt (WMA) technologies has been developed to alleviate the workability concern of asphalt mixtures [10-12]. According to different working mechanisms, WMA can be divided into three categories: (i) foaming processes (using water foaming or foaming additives to decrease the binder viscosity by enlarging binder the volume); (ii) the addition of organic additives (using wax as a flow improver to reduce the binder viscosity at the mixing temperature); and (iii) the addition of chemical additives (using surfactant agents to reduce binder-aggregate friction for easier coating). It is reported that with the aid of WMA additives, AR mixtures can be paved at a similar temperature $\left(160^{\circ} \mathrm{C}\right)$ to that used for conventional asphalt mixes [13]. Compared to AR, warm asphalt rubber (WAR) has more complex components and its rheological and mechanical properties are also influenced by the properties of WMA additives.

Many studies have been conducted for mechanism investigation and performance evaluation of WAR [7,12-21]. For example, Yu et al. found that organic and chemical additives promoted the dissolution of CRM in asphalt fractions [12]. Leng et al. found that during the blending process at a high temperature, CRM absorbs not only asphalt light fractions but also part of the components from organic additives [7]. The workability enhancing effect of WMA additives on AR are significant [14]. The mechanical performance evaluation always involves both binder and mixture tests. Akisetty et al. reported that although the mixture performance may be affected by aggregate properties, the mixture test results have relatively good consistency with binder rheological characteristics [15]. For high temperature performance, the results of binder tests (both $\mathrm{G}^{*} / \sin \delta$ by temperature sweep and $\mathrm{J}_{\mathrm{nr}} 3.2$ by multiple stress creep and recovery) showed good consistence with those of mixture rutting tests. Among different WMA additives, commercial organic additives (Sasobit, Licomont, and Asphaltan) were found to enhance rutting resistance while foaming additives (Aspha-min) exerted an indistinct effect $[16,17]$. One chemical additive, Evotherm-DAT, was reported to negatively affect rutting resistance [18] while another chemical additive used in Brazil showed limited influence on rutting performance [19]. In terms of fatigue behavior, both the asphalt rubber binder and mixture showed superior performance compared to the conventional ones [20]. However, for fatigue characterization, the author's previous study showed that the ITFT results of WAR mixtures (AR with organic additive performed worse) did not correlated well with the Superpave fatigue test results of their corresponding WAR binders (AR with wax additive performed best) [13]. One potential explanation for this is that the $G^{*} \sin \delta$ value cannot precisely characterize the fatigue property, since this parameter is based on linear viscoelastic properties but not cracking resistance [21]. Meanwhile, the inconsistency may be ascribed to the complicated influence of various WMA additives on asphalt-aggregate adhesion.

To this end, the objective of this study is to gain a more comprehensive understanding of the fatigue behavior of WAR with different WMA additives. A series of fatigue tests were conducted on WAR binder, mortar, and mixture specimens. The results of different fatigue tests were summarized and analyzed. This paper is also expected to provide reference to select fatigue-evaluating approaches for rubberized asphalt materials. 


\section{Materials and Methods}

\subsection{Sample Preparation and Lab-Simulated Aging}

\subsubsection{Binder}

Asphalt with a penetration grade of $60 / 70$ (Pen60/70, 2017, Shell, Singapore) was selected as the raw bitumen to produce AR and WAR binders. AR binder was prepared by blending $18 \%$ of 40 -mesh crumb rubber by the total weight of base asphalt and crumb rubber with base asphalt at $176{ }^{\circ} \mathrm{C}$ and $4000 \mathrm{r} / \mathrm{min}$ for $1 \mathrm{~h}$ using a high shear mixer. WAR binders were produced with three WMA additives with different working mechanisms, namely Sasobit (organic additive, Sasol-Wax Co. Ltd., Hamburg, Germany), Evotherm-DAT (chemical additive, MeadWestvaco Co. Ltd., Richmond, VA, USA), and Asphalt-min (foaming additive, Eurovia GmbH Co. Ltd., Berlin, Germany). Table 1 shows the physical properties of the selected WMA additives. The prepared samples with different WMA additives were labeled as ARE (with Evotherm-DAT), ARS (with Sasobit), and ARA (with Asphalt-min), respectively. Right after the blending process of AR binder, the WAR binders were produced by adding WMA additives via high shear mixing at $160{ }^{\circ} \mathrm{C}$ for $10 \mathrm{~min}$. The material dosage and preparing procedure were determined based on both preliminary test results and recommendations of WMA manufacturers [20,22]. Before the fatigue tests, AR and WAR binders were lab-simulated aged by both standard rolling thin film oven (RTFO) and pressure aging vessel (PAV) processes [23,24].

Table 1. Physical properties of selected warm mix asphalt (WMA) additives.

\begin{tabular}{cccc}
\hline Properties & Evotherm-DAT & Sasobit & Aspha-Min \\
\hline Ingredients & Fatty amine derivatives, & Solid saturated & hydrocarbons \\
alkylamines & Solid & Zeolite, water \\
State & Liquid & Milky-white & Solid \\
Color & Caramel & None & White \\
Odor & Amine-like & $0.622 \mathrm{~g} / \mathrm{cm}^{3}$ & None \\
Density & $>1.0 \mathrm{~g} / \mathrm{cm}^{3}$ & $\mathrm{~N} / \mathrm{A}$ & $1.57 \mathrm{~g} / \mathrm{cm}^{3}$ \\
PH value & $9-10$ & $\mathrm{~N} / \mathrm{A}$ & $\mathrm{N} / \mathrm{A}$ \\
Boiling point & $150-170{ }^{\circ} \mathrm{C}$ & $\mathrm{N} / \mathrm{A}$ \\
Melting point & $\mathrm{N} / \mathrm{A}$ & $\mathrm{N} / \mathrm{A}$ \\
Water solubility & Partially soluble & Insoluble & Insoluble \\
Dosage & $5 \mathrm{wt} \%$ of AR binder & $3 \mathrm{wt} \%$ of AR binder & $5 \mathrm{wt} \%$ of AR binder \\
\hline
\end{tabular}

\subsubsection{Mortar}

For asphalt mortar preparation, a certain percentage of asphalt binders, fine aggregates (with a size less than $1.18 \mathrm{~mm}$ ), and fillers were completely blended at either $176{ }^{\circ} \mathrm{C}$ (with AR binder) or $160{ }^{\circ} \mathrm{C}$ (with WAR binders). The asphalt content $(12 \%)$ and gradation of aggregates were decided by referring to a previous study [3]. The mixed material was lab-simulated aged by in an oven at $165^{\circ} \mathrm{C}$ for $2 \mathrm{~h}$ (short-term aging) and then in a PAV for $80 \mathrm{~h}\left(2.1 \mathrm{MPa}, 100^{\circ} \mathrm{C}\right)$. For one aging process, about $60 \mathrm{~g}$ of asphalt mortar was placed on one standard PAV steel plate. After the aging process, cylindrical specimens (diameter $\mathrm{d}=100 \mathrm{~mm}$, height $\mathrm{h}=40 \mathrm{~mm}$ ) were prepared using a Superpave gyration compacter (SGC). Afterwards, the mortar specimens (diameter $\mathrm{d}=10 \mathrm{~mm}$, height $\mathrm{h}=25 \mathrm{~mm}$ ) were produced by mechanical drilling and sawing from the SGC samples. A self-designed device was used to place the mortar samples on a dynamic shear rheometer (DSR).

\subsubsection{Mixture}

For asphalt mixture preparation, Stone Mastic Asphalt 10 (SMA10) gradation commonly applied in South China was used. Detail information of gradation can be found in another publication of the corresponding author [13]. The mixing temperatures were set as $176{ }^{\circ} \mathrm{C}$ for AR mixtures and $160^{\circ} \mathrm{C}$ for WAR mixtures, and the compacting temperatures were approximately $15^{\circ} \mathrm{C}$ lower. 
The blending process of binder, aggregate, and mineral fillers was conducted right after the binder preparation. Two different specimens were prepared, cylindrical specimens (diameter $d=100 \mathrm{~mm}$, height $\mathrm{h}=40 \mathrm{~mm}$ ) for the ITFT and prismatic specimens $(380 \mathrm{~mm} \times 63.5 \mathrm{~mm} \times 50 \mathrm{~mm})$ for the 4 PB test. The lab-simulated aging process for asphalt mixtures was performed according to AASHTO R30 [25]. For lab-simulated aging, all testing specimens were placed in an oven at $85{ }^{\circ} \mathrm{C}$ for 5 days before fatigue testing.

\subsection{Testing Program}

\subsubsection{Binder}

The binder fatigue properties were evaluated by the Superpave fatigue factor $\left(G^{*} \sin \delta\right)$ test and LAS test (Figure 1a), using a dynamic shear rheometer (DSR, Malvern Instruments Ltd., Malvern, Worcestershire, UK) [2]. The fatigue factor test consists of a temperature sweep starting at $25^{\circ} \mathrm{C}$ with a decrement of $3{ }^{\circ} \mathrm{C}$ until the fatigue factor exceeds $5000 \mathrm{kPa}$ [1]. The LAS test was performed at $25^{\circ} \mathrm{C}$, aiming to decide the parameters of the asphalt binder fatigue law $\left(\mathrm{N}_{\mathrm{f}}=\mathrm{A}\left(\gamma_{\max }\right)^{\mathrm{B}}\right)$. The LAS test consists of one frequency sweep and one amplitude sweep. The aim of the frequency sweep $(0.1 \%$ amplitude strain level) is to obtain undamaged material properties and the parameter $b$, while the aim of the amplitude sweep with a series of cyclic loading at systematically linearly increasing strain amplitudes at a constant frequency of $10 \mathrm{~Hz}$ is to determine the parameter a by viscoelastic continuum damage (VECD) mechanics analysis. For the linear amplitude sweep test, loading begins with 100 cycles of sinusoidal loading at $0.1 \%$. Each successive loading step consists of 100 cycles at a rate of increase of $1 \%$ applied strain until it reaches $30 \%$ applied strain [26]. To alleviate the influence of the swelled rubber's particle effect, a 2-mm plate gap was used for all rubberized binder specimens during the DSR tests [27]. For each type of asphalt, three replicates were prepared and tested.

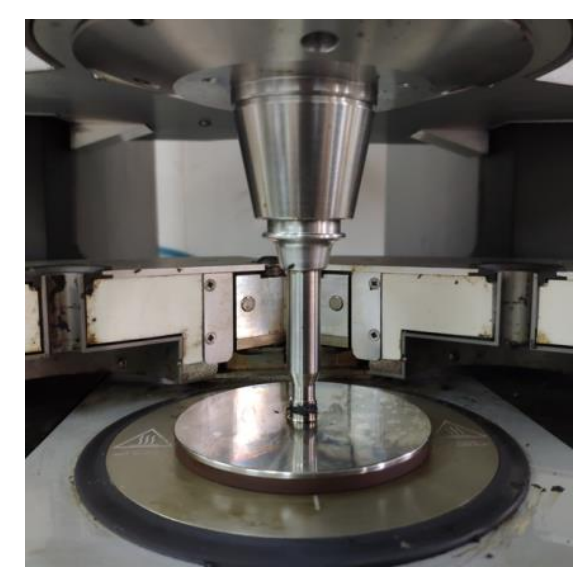

(a)

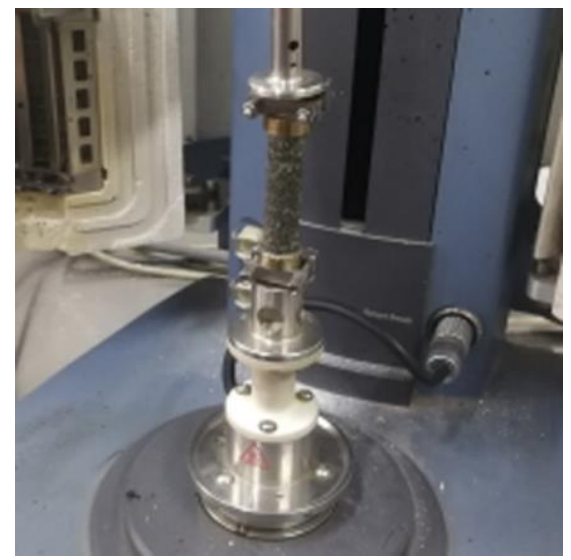

(b)

Figure 1. Fatigue characterizing tests: (a) $G^{*} \sin \delta$ and linear amplitude sweep (LAS) test for binders; (b) shear fatigue test for mortars.

\subsubsection{Mortar}

The shear fatigue test was performed to characterize the fatigue resistance of rubberized asphalt mortars (Figure 1b). During the test, a continuous oscillating deformation was applied to the mortar sample until the test sample was damaged. Five different shear strain levels (0.6 to 1.0, with increments of 0.1 ), which were high enough to develop fatigue damage (determined by the amplitude sweep test in advance), were chosen for asphalt mortars in shear fatigue tests. The tests were conducted at $10^{\circ} \mathrm{C}$ with a fixed loading frequency of $10 \mathrm{~Hz}$ [3]. The initial stiffness is the specimen stiffness at the 50th load cycle. The failure criterion based on the $50 \%$ of initial stiffness method is used for the mortar shear 
fatigue test under the strain-controlled mode. In other words, the test is terminated automatically when the measured stiffness has diminished by $50 \%$ compared to the initial stiffness.

\subsubsection{Mixture}

The ITFT of asphalt mixtures was conducted using a Nottingham Asphalt Tester (NAT-10, developed by University of Nottingham, Nottingham, UK, Figure 2a). The testing temperature was controlled at $25 \pm 0.5^{\circ} \mathrm{C}$. The tester uses a haversine loading waveform with a rise time of $124 \mathrm{~ms}$ at a pulse frequency of approximately $0.67 \mathrm{~Hz}$. The fatigue life is defined as the total number of loading applications that causes a fracture of the specimen. During the ITFT, the specimens were subjected to a sinusoidally oscillating axial loading in tension. The tests were performed in controlled strain modes. For each type of mixture, the ITFT was conducted at seven different strain levels (250 to 800, different from samples). The relationship between the tensile stress and the number of cycles to failure for each material was established [4].

The 4PB test of asphalt mixtures was conducted using a Cooper NU-14 tester (Cooper Research Technology-Technical Centre, Ripley, Derbyshire, UK), according to AASHTO T321 (Figure 2b) [5]. The tests were performed at $15 \pm 0.5^{\circ} \mathrm{C}$. A strain level of 600 microstrains and a loading frequency of $10 \mathrm{~Hz}$ were used. During each load cycle beam, deflections were measured at the center of the beam to calculate the maximum tensile stress, maximum tensile strain, phase angle, stiffness, dissipated energy, and cumulative dissipated energy. Failure is assumed to occur when the stiffness has reached half of its initial value, which is determined from the load at approximately 50 repetitions; the test is terminated automatically when this load has diminished by $50 \%$.

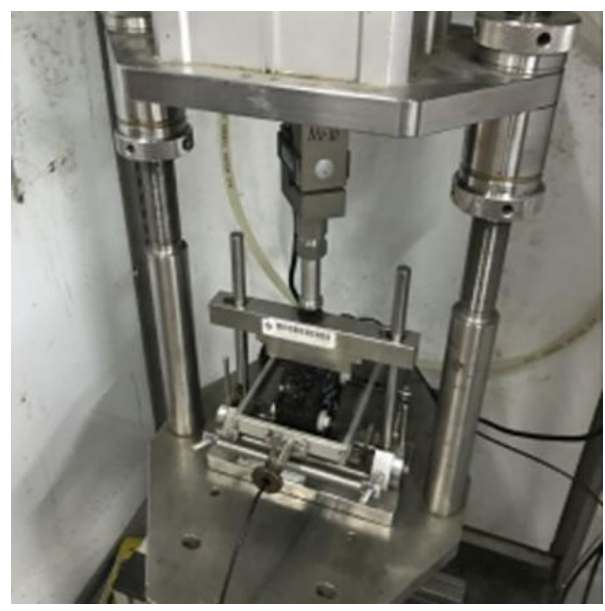

(a)

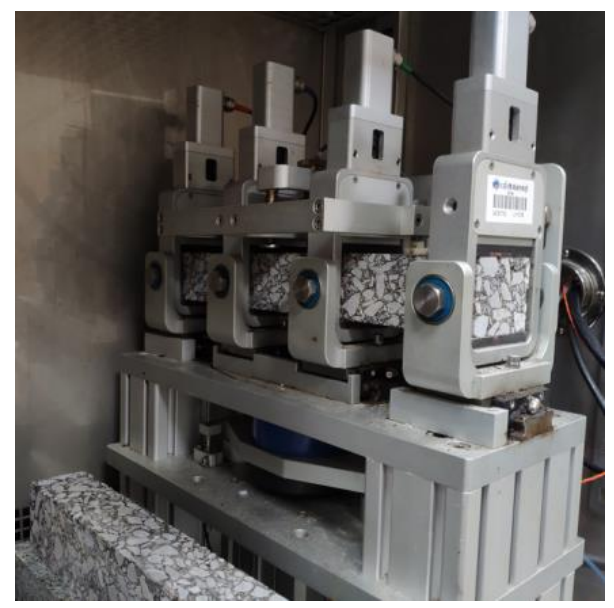

(b)

Figure 2. Fatigue characterizing tests: (a) indirect tensile fatigue test (ITFT) test for mixtures; (b) 4PB test for mixtures.

\section{Results}

\subsection{Binders}

\subsection{1. $G^{*} \sin \delta$}

Figure 3 shows the results of the Superpave fatigue factor test. As expected, the Superpave fatigue factor $\left(G^{*} \sin \delta\right)$ increased with decreasing temperature, indicating that fatigue failure is more inclined to happen in cooler conditions (Figure 3a). As noted in Figure 3b, the threshold temperature of Pen60/70 is $22{ }^{\circ} \mathrm{C}$, the highest among all test samples, showing the poorest fatigue resistance. The incorporation of crumb rubber significantly enhanced the fatigue performance. The failure temperature of AR binder 
is almost $12{ }^{\circ} \mathrm{C}$ lower than that of Pen60/70. The $\mathrm{G}^{*} \sin \delta$ also indicated that all three WMA additives had a negative impact on the fatigue resistance of AR. Among the WAR binders, ARS had the best fatigue resistance among the WAR binders. Compared to ARS, the threshold temperatures of ARE and ARA binders were $3.4^{\circ} \mathrm{C}$ and $3.3^{\circ} \mathrm{C}$ higher, respectively.

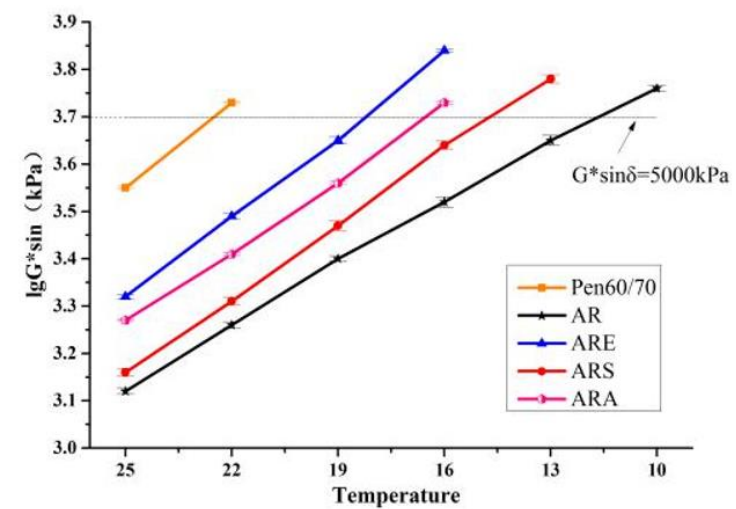

(a)

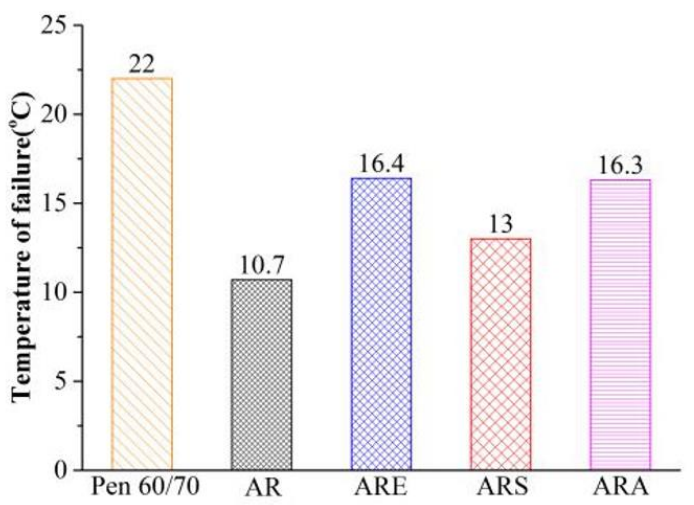

(b)

Figure 3. Superpave fatigue factor test results: (a) $\mathrm{G}^{*} \sin \delta$ values; (b) failure temperatures.

\subsubsection{LAS}

Figure 4 shows the LAS test results. The number of cycles to failure $\left(\mathrm{N}_{\mathrm{f}}\right)$ at both the strain levels of $2.5 \%$ (Figure $4 \mathrm{a}$ ) and $5.0 \%$ (Figure $4 \mathrm{~b}$ ) are presented. A higher $\mathrm{N}_{\mathrm{f}}$ indicates superior resistance to fatigue cracking in the tested strain level. According to Figure 4, Pen60/70 had the fewest loading cycles to failure at both of the strain levels, indicating the poorest fatigue performance. Among the rubberized binders, the most outstanding fatigue resistance was observed with ARS binder, followed by AR, ARE, and ARA binders. The fatigue performance of the test binders was consistent at both the low strain level $(2.5 \%)$ and high strain level (5\%). Different from the $\mathrm{G}^{*} \sin \delta$ results, ARS outperformed AR in the LAS test. Moreover, among the WAR binders, the fatigue performance indicated by the LAS test and Superpave fatigue factor test were also conflicting.

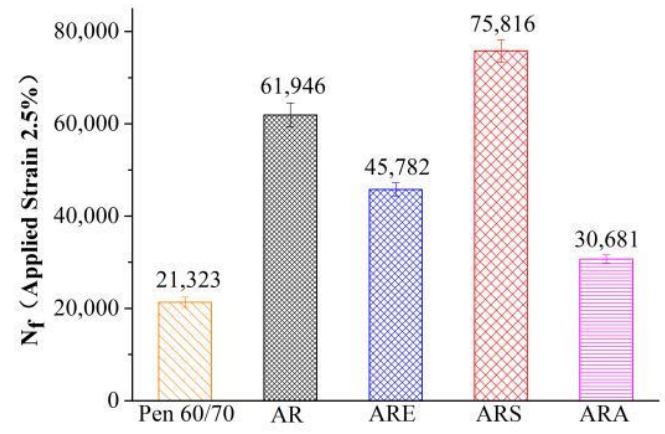

(a)

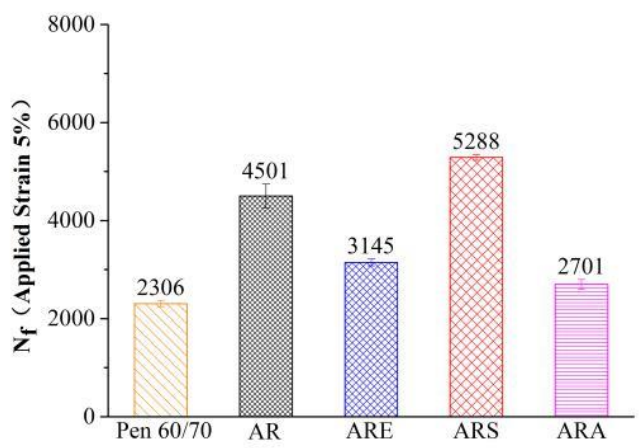

(b)

Figure 4. Results of the LAS test with different applied strains: (a) $2.5 \%$ and (b) $5 \%$.

\subsection{Mortars}

Figure 5 shows the fatigue lives of WAR mortars at five applied strain levels recorded by the DSR testing system. Higher loading cycles to fatigue failure indicate superior fatigue resistance. In general, 
the Pen60/70 samples performed worse at all strain levels. However, at the high strain level (1\%), the fatigue lives of the test specimens were relatively close to each other, especially for Pen60/70, ARE, and ARA samples. The differences of cycles to fatigue among different specimens were more distinct with decreasing strain levels. Among the rubberized mortars, ARS had the longest fatigue lives at all strain levels, followed by AR, ARE, and ARA mortars. The fatigue resistance ranking indicated by the mortar test is consistent with the results of the LAS test of WAR binders.

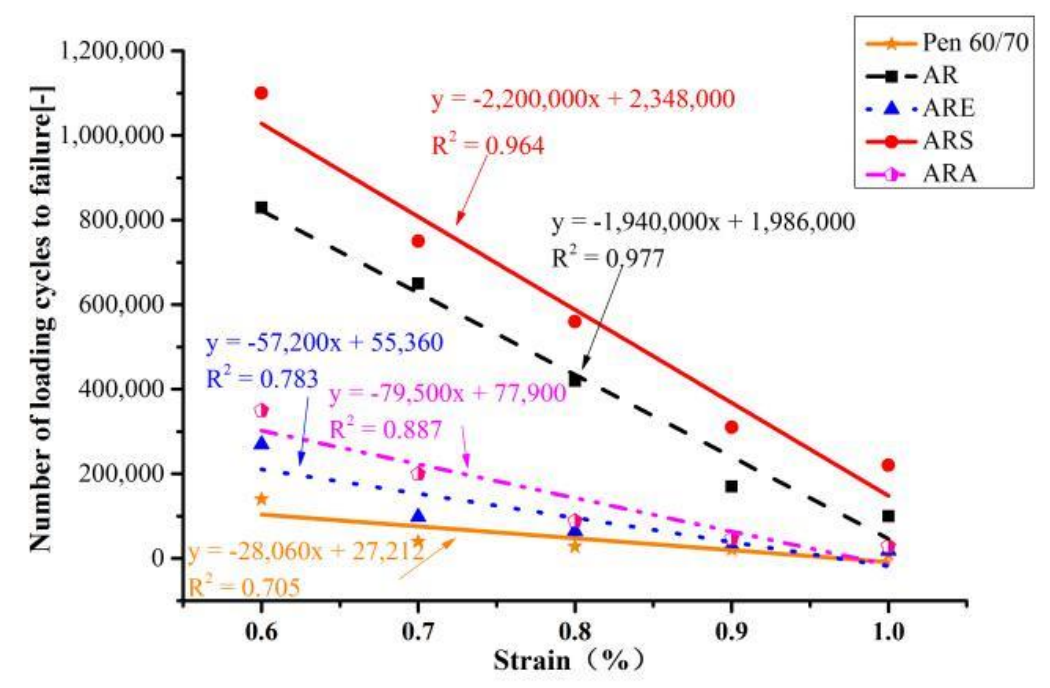

Figure 5. Shear fatigue test result for asphalt mortars.

\subsection{Mixtures}

\subsubsection{ITFT}

A linear relationship between log (cycles to failure) and log (microstrain, $\xi$ ) can be obtained using the data of the ITFT results, as illustrated in Figure 6. According to previous research, the tensile strains generated under a standard axle load at the bottom of the asphalt layer always ranges from 0 and 200 microstrains [13]. To analyze the ITFT results, two microstrain values (100 and 200) were considered in this research, representing the normal and high strain levels, respectively. Table 2 provides the "cycles at 100/200 microstrains" of each mixture (labeled as $\mathrm{N}_{\mathrm{f} 100}$ and $\mathrm{N}_{\mathrm{f} 200}$ ). A larger number of cycles at the same microstrain indicates a longer fatigue life. Based on Table 2, at both strain levels the fatigue performance of rubberized mixtures was superior to that of the Pen60/70 mixture. Among the WAR mixtures, only ARE mixture had a longer fatigue life than AR mixture. ARA and ARS mixtures had similar fatigue performance, and ARS mixture had the worst resistance to fatigue at both microstrains.

Table 2. Results of the indirect tensile fatigue test (ITFT).

\begin{tabular}{ccccccc}
\hline \multirow{2}{*}{$\begin{array}{c}\text { Mixture } \\
\text { Types }\end{array}$} & \multicolumn{3}{c}{$\mathbf{N}_{\mathbf{f}}=\mathbf{k}_{\mathbf{1}}(\xi)^{\mathbf{k}_{\mathbf{2}}}$ or $\log \mathbf{N}_{\mathbf{f}}=\mathbf{l o g} \mathbf{k}_{\mathbf{1}}+\mathbf{k}_{\mathbf{2}} \log \boldsymbol{\xi}$} & \multicolumn{2}{c}{ Failure Cycles } \\
\cline { 2 - 7 } & $\mathbf{l o g} \mathbf{k}_{\mathbf{1}}$ & $\mathbf{k}_{\mathbf{1}}$ & $\mathbf{k}_{\mathbf{2}}$ & $\mathbf{R}^{\mathbf{2}}$ & Microstrain = 100 & Microstrain = 200 \\
\hline Pen60/70 & 7.7886 & $6.14611 \times 10^{7}$ & -1.8937 & 0.97460 & $1.03 \times 10^{4}$ & $2.70 \times 10^{3}$ \\
AR & 15.00943 & $1.02195 \times 10^{15}$ & -4.41648 & 0.84440 & $1.50 \times 10^{6}$ & $7.03 \times 10^{4}$ \\
ARE & 13.05896 & $1.14541 \times 10^{13}$ & -3.37453 & 0.95901 & $2.04 \times 10^{6}$ & $1.97 \times 10^{5}$ \\
ARS & 11.90274 & $7.99356 \times 10^{11}$ & -3.18268 & 0.96721 & $3.45 \times 10^{5}$ & $3.80 \times 10^{4}$ \\
ARA & 11.46023 & $2.88556 \times 10^{11}$ & -2.90851 & 0.80283 & $4.40 \times 10^{5}$ & $5.86 \times 10^{4}$ \\
\hline
\end{tabular}




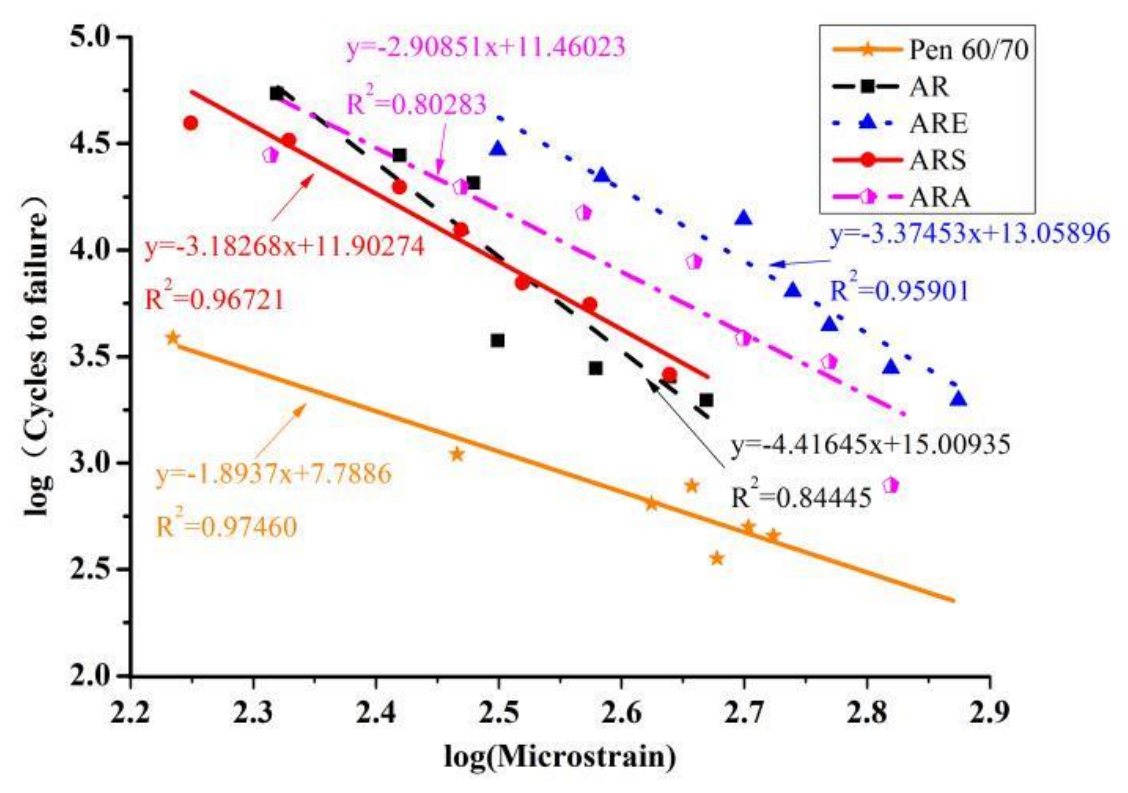

Figure 6. ITFT measurements for mixtures.

\subsection{2. $4 \mathrm{~PB}$}

For the four-point beam fatigue test, the fatigue life of a mixture specimen refers to the number of cycles it takes to achieve a 50\% reduction in the initial stiffness. The initial stiffness was measured at the 50th load cycle. Figure 7 presents the $4 \mathrm{~PB}$ test results. As expected, the rubberized mixtures exhibited larger cycle numbers to failure, indicating that the rubberized samples have a longer fatigue life. ARS mixture showed the best fatigue performance. AR mixture had better fatigue resistance than ARE and ARA mixtures. The fatigue performance ranking obtained from the 4PB test was consistent with those from the binder LAS test and mortar shear fatigue test. However, the discrepancy between the $4 \mathrm{~PB}$ test and ITFT rankings was fairly high.

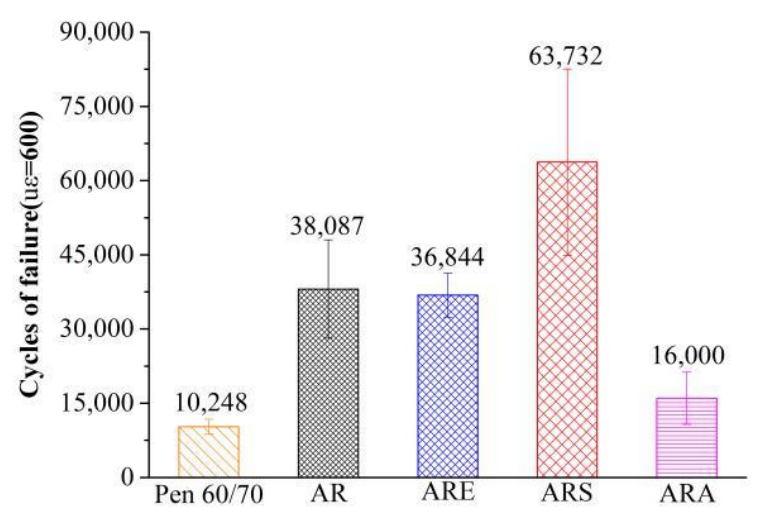

Figure 7. Four-point beam (4PB) test results.

\section{Discussion}

The fatigue behavior (at intermediate temperatures) of Pen60/70, AR and WAR binders, mortars, and mixtures were characterized by binder, mortar, and mixture tests. CRM had remarkable enhancing effects on the fatigue performance at intermediate temperatures. Table 3 briefly summarizes the ranking results of the five fatigue tests. It is noted that results of the LAS, shear fatigue test, and $4 \mathrm{~PB}$ test ranked the asphalt binders and their corresponding asphalt mixtures exactly the same (ARS > AR > ARE $>$ 
ARA $>$ Pen60/70). Although Sasobit improved the binder stiffness, ARS samples were found to have the best fatigue resistance. This enhanced performance may be attributed to the crystalline network structure of the Sasobit additive, which stabilizes the asphalt fractions. However, the enhancing mechanism of Sasobit is as yet unclear; chemical and micro analyses are recommended for mechanism investigation. Evotherm-DAT and Aspha-min had certain negative effects on fatigue resistance. The liquid components in the chemical and foaming additives may not be completely evaporated during the mixing and compacting processes. The residual water may result in a poorer adhesive capability between binder and aggregates, which leads to poorer fatigue resistance.

Table 3. Fatigue performance ranking of test binders obtained from different tests.

\begin{tabular}{cccccc}
\hline \multirow{2}{*}{ Binder Type } & \multicolumn{5}{c}{ Ranking by Different Evaluating Approaches } \\
\cline { 2 - 6 } & G*$^{*} \sin \delta$ & LAS & Mortar & ITFT & 4PB \\
\hline Pen60/70 & 5 & 5 & 5 & 5 & 5 \\
AR & 1 & 2 & 2 & 2 & 2 \\
ARE & 4 & 3 & 3 & 1 & 3 \\
ARS & 2 & 1 & 1 & 4 & 1 \\
ARA & 3 & 4 & 4 & 3 & 4 \\
\hline
\end{tabular}

By comparison, the Superpave fatigue factor test and ITFT indicated different conclusions. For the Superpave fatigue test results, AR performed better than ARS, and ARA slightly outperformed ARE. The other rankings were almost same as those of other parameters, apart from those obtained by the ITFT. Previous studies have reported that the $G^{*} \sin \delta$ is not an accurate indicator of asphalt mixtures' fatigue performance [28,29]. According to its mechanism, $G^{*} \sin \delta$ is a stiffness-based parameter. This parameter is measured under the condition of a small shear strain and a constant loading frequency, and can only undergo several loading cycles without fatigue damage. The simulated condition is obviously different from the complicated fatigue phenomenon observed with large numbers of loading cycles and fatigue damage [29]. The influence of the Sasobit additive on asphalt stiffness may be the reason why the $G^{*} \sin \delta$ value of ARS is larger than that of AR. This study further confirmed the poor performance of the $G^{*} \sin \delta$ test. By comparison, the LAS test was proven to be a better fatigue indicator for rubberized binders.

It is unexpected to notice that the ITFT provided completely different conclusions as compared to the other tests. One possible explanation for this is that the resilient crumb rubber particles led to the local distortion of the place in touch with the fixers, which resulted in the actual fracture mode being inconsistent with the theoretical mode. Moreover, the loading mode of the ITFT is different from the real loading status under traffic conditions. Therefore, the four-point bending test is a more reliable fatigue characterization for rubberized mixtures.

\section{Conclusions}

This study presents a fatigue behavior characterization of warm asphalt rubbers by five different evaluating approaches, including the $G^{*} \sin \delta$ and LAS tests for binders, shear fatigue test for mortars, and ITFT and 4PB tests for mixtures. Based on the experimental results and analysis, the following findings were obtained:

Crumb rubber modifier significantly enhances the fatigue resistance. All five used parameters consistently verified the fatigue performance enhancement brought by crumb rubber. WAR specimens have shorter fatigue lives compared to AR, except those with the Sasobit additive.

The LAS, mortar shear fatigue test, and $4 \mathrm{~PB}$ test provided the same prediction of fatigue resistance, while the results of the $G^{*} \sin \delta$ test and ITFT were inconsistent with the others. It is recommended to use LAS, mortar shear fatigue test, and $4 \mathrm{~PB}$ test for the fatigue evaluation of rubberized binders and mixtures. 
It is worth mentioning that the above findings are based on laboratory evaluation only. Future research on field validation is strongly suggested. In addition, the parameters applied in this study can only be used to characterize the fatigue property of specific asphalt binders or mixtures. The fatigue life of asphalt pavement is determined by both the internal factors (material properties) and external factors (traffic and environmental conditions).

Author Contributions: Experiments design, J.Y. and H.Y.; Performing Experiments, X.Y.; Formal Analysis, X.Y., F.G., D.W.; Paper Writing, H.Y. and Z.G.

Funding: This research was funded by the National Natural Science Foundation of China, grant number NSFC 51678251, NSFC 51808228.

Acknowledgments: The authors would like to thank the technicians in the Road laboratories of South China University of Technology, Meijuan Hu, Fuda Chen, Shenghui Zhu, for their technical support and assistance in experimental activities.

Conflicts of Interest: The authors declare no conflict of interest. The founding sponsors had no role in the design of the study; in the collection, analyses, or interpretation of data; in the writing of the manuscript, and in the decision to publish the results.

\section{References}

1. American Association of State and Highway Transportation Officials. Grading or Verifying the performance grade (PG) of an asphalt binder. In AASHTO Standard R 29; American Association of State and Highway Transportation Officials: Washington, DC, USA, 2013.

2. Association of State and Highway Transportation Officials. Estimating fatigue resistance of asphalt binders using the linear amplitude sweep. In AASHTO Standard TP 101; American Association of State and Highway Transportation Officials: Washington, DC, USA, 2013.

3. Zhang, Y.; Leng, Z. Quantification of bituminous mortar aging and its application in ravelling evaluation of porous asphalt wearing courses. Mater. Des. 2017, 119, 1-11. [CrossRef]

4. DIN Standards Committee Building and Civil Engineering. Test methods-Part 24: Resistance to fatigue (German version EN 12697-24:2018). In Bituminous Mixtures; DIN Standards Committee Building and Civil Engineering: Berlin, Germany, 2018.

5. Association of State and Highway Transportation Officials. Determining the fatigue life of compacted hot mix asphalt (HMA) subjected to repeated flexural bending. In AASHTO Standard T 321; American Association of State and Highway Transportation Officials: Washington, DC, USA, 2013.

6. Shu, X.; Huang, B.; Vukosavljevic, D. Laboratory evaluation of fatigue characteristics of recycled asphalt mixture. Constr. Build. Mater. 2008, 22, 1323-1330. [CrossRef]

7. Leng, Z.; Yu, H.; Zhang, Z.; Tan, Z. Optimizing the mixing procedure of warm asphalt rubber with wax-based additives through mechanism investigation and performance characterization. Constr. Build. Mater. 2017, 144, 291-299. [CrossRef]

8. Venudharan, V.; Biligiri, K.P.; Sousa, J.B.; Way, G.B. Asphalt-rubber gap-graded mixture design practices: A state-of-the-art research review and future perspective. Road Mater. Pavement Des. 2017, 18, 730-752. [CrossRef]

9. Freitas, E.F. The effect of time on the contribution of asphalt rubber mixtures to noise abatement. Noise Control Eng. J. 2012, 60, 1-8. [CrossRef]

10. Pasetto, M.; Pasquini, E.; Giacomello, G.; Baliello, A. Sustainable solutions for road pavements: A multi-scale characterization of warm mix asphalts containing steel slags. J. Clean. Prod. 2017, 166, 835-843. [CrossRef]

11. Pasetto, M.; Pasquini, E.; Giacomello, G.; Baliello, A. Warm chemical additive to improve water resistance of asphalt mixtures containing steel slags: A multi-scale approach. Int. J. Pavement Eng. Infrastruct. 2017, 18, 26-39.

12. Shu, X.; Huang, B. Recycling of waste tire rubber in asphalt and Portland cement concrete: An overview. Constr. Build. Mater. 2014, 67, 217-224. [CrossRef]

13. Yu, H.; Leng, Z.; Dong, Z.; Tan, Z.; Guo, F.; Yan, J. Workability and mechanical property characterization of asphalt rubber mixtures modified with various warm mix asphalt additives. Constr. Build. Mater. 2018, 175, 392-401. [CrossRef] 
14. Wang, H.; Dang, Z.; You, Z.; Cao, D. Effect of warm mixture asphalt (WMA) additives on high failure temperature properties for crumb rubber modified (CRM) binders. Constr. Build. Mater. 2012, 35, $281-288$. [CrossRef]

15. Akisetty, C.; Xiao, F.; Gandhi, T.; Amirkhanian, S. Estimating correlations between rheological and engineering properties of rubberized asphalt concrete mixtures containing warm mix asphalt additive. Constr. Build. Mater. 2011, 25, 950-956. [CrossRef]

16. Rodríguez-Alloza, A.M.; Gallego, J.; Perez, I. Study of the effect of four warm mix asphalt additives on bitumen modified with 15\% crumb rubber. Constr. Build. Mater. 2013, 43, 300-308. [CrossRef]

17. Akisetty, C.K.; Lee, S.J.; Amirkhanian, S.N. High temperature properties of rubberized binders containing warm asphalt additives. Constr. Build. Mater. 2009, 23, 565-573. [CrossRef]

18. Yu, H.; Leng, Z.; Xiao, F.; Gao, Z. Rheological and chemical characteristics of rubberized binders with non-foaming warm mix additives. Constr. Build. Mater. 2016, 111, 671-678. [CrossRef]

19. Oliveira, J.R.M.; Silva, H.M.R.D.; Abreu, L.P.F.; Fernandes, S.R.M. Use of a warm mix asphalt additive to reduce the production temperatures and to improve the performance of asphalt rubber mixtures. J. Clean. Prod. 2013, 41, 15-22. [CrossRef]

20. Xiao, F.; Zhao, P.E.W.; Amirkhanian, S.N. Fatigue behavior of rubberized asphalt concrete mixtures containing warm asphalt additives. Constr. Build. Mater. 2009, 23, 3144-3151. [CrossRef]

21. Zhou, F.; Mogawer, W.; Li, H.; Andriescu, A.; Copeland, A. Evaluation of fatigue tests for characterizing asphalt binders. J. Mater. Civ. Eng. 2012, 25, 610-617. [CrossRef]

22. Yu, H.; Leng, Z.; Zhou, Z.; Shih, K.; Xiao, F.; Gao, Z. Optimization of preparation procedure of liquid warm mix additive modified asphalt rubber. J. Clean. Prod. 2017, 141, 336-345. [CrossRef]

23. American Association of State and Highway Transportation Officials. Effect of heat and air on a moving film of asphalt binder (rolling thin-film oven test). In AASHTO Standard T 240; American Association of State and Highway Transportation Officials: Washington, DC, USA, 2013.

24. American Association of State and Highway Transportation Officials. Accelerated aging of asphalt binder using a pressurized aging vessel. In AASHTO Standard R 28; American Association of State and Highway Transportation Officials: Washington, DC, USA, 2013.

25. American Association of State and Highway Transportation Officials. Standard practice for mixture conditioning of hot mix asphalt (HMA). In AASHTO Standard R30; American Association of State and Highway Transportation Officials: Washington, DC, USA, 2002.

26. Sabouri, M.; Mirzaeian, D.; Moniri, A. Effectiveness of linear amplitude sweep (LAS) asphalt binder test in predicting asphalt mixtures fatigue performance. Constr. Build. Mater. 2018, 171, 281-290. [CrossRef]

27. Teymourpour, P.; Hanz, A.J.; Mandal, T.; Bahia, H.; Rizzutto, S.J. Effect of parallel plate gap height on repeatability in DSR measurements of crumb-rubber modified binders. J. Mater. Civ. Eng. 2016, 28, 04016047. [CrossRef]

28. Mannan, U.A.; Islam, M.R.; Tarefder, R.A. Effects of recycled asphalt pavements on the fatigue life of asphalt under different strain levels and loading frequencies. Int. J. Fatigue 2015, 78, 72-80. [CrossRef]

29. Hintz, C.; Bahia, H. Understanding mechanisms leading to asphalt binder fatigue in the dynamic shear rheometer. Road Mater. Pavement Des. 2013, 14, 231-251. [CrossRef]

(C) 2018 by the authors. Licensee MDPI, Basel, Switzerland. This article is an open access article distributed under the terms and conditions of the Creative Commons Attribution (CC BY) license (http://creativecommons.org/licenses/by/4.0/). 